\title{
Influence of Dosages of Biofertilizers Composed of Mycorrhizae and Diazotrophs on the Corn Productivity
}

\section{Influencia de Dosificaciones de Biofer- tilizantes Compuestos por Micorrizas y Diazótrofos Sobre La Productividad Del Maíz}

\author{
Jordan Joao Palacios Zambrano and Vianka Stéfany García García
}

I International Congress of Science and Technology Morona Santiago-CICTMS 2020

Corresponding Author:

Jordan Joao Palacios

Zambrano

palaciosjoao1998@gmail.com

Published: 29 August 2021

Production and Hosting by

Knowledge E

(c) Jordan Joao Palacios

Zambrano and Vianka

Stéfany García García. This

article is distributed under the terms of the Creative Commons Attribution License, which permits unrestricted use and redistribution provided that the original author and source are credited.
S OPEN ACCESS
Universidad Laica Eloy Alfaro de Manabí, Facultad de Ciencias Agropecuarias, Carrera de Ingeniería Agropecuaria, Manta, Ecuador

\section{Abstract}

Corn (Zea mays L.) is a crop of world importance, however, one of the problems present during its development is the lack of nutrients or the presence of these in a form not available to the plant. Because of this, the objective of this review article is to gather information on the influence of different dosages of mycorrhiza and diazotroph biofertilizers on the corn crop. A meticulous bibliographic research was carried out, detailing the methods used by various authors; Among the most repetitive and significant factors are the use of mycorrhizae and nitrogen-fixing bacteria plus fertilization with $\mathrm{P}$, the following treatment stands out: $200 \mathrm{gr} \mathrm{ha}^{-1}$ (using mycorrhizae and nitrogen-fixing bacteria); the common response variable of the authors mentioned in methodology was grain yield. The results obtained by the majority of authors show that grain yield improves significantly in the interaction of mycorrhizae and diazotrophs plus chemical fertilization; As a result of the aforementioned treatment, the yield of corn $\mathrm{kg}$ $\mathrm{ha}^{-1}$ was increased by $37 \%$, by virtue of these results it is concluded that the most appropriate thing would be to take it into account to apply it on the corn crop.

Keywords: Inoculants, Nitrogen Fixing Bacteria, Symbiotic Fungi

\section{Resumen}

El maíz (Zea mays L.) es un cultivo de importancia mundial, sin embargo, uno de los problemas presentes durante su desarrollo, es la falta de nutrientes o la presencia de estos en forma no disponible para la planta. Debido a esto, el objetivo de este artículo de revisión es recopilar información sobre la influencia de las diferentes dosificaciones de biofertilizantes a base de micorriza y diazótrofos sobre el cultivo de maíz. Se realizó una minuciosa investigación bibliográfica, detallando métodos utilizados por varios autores; entre los factores más reiterativos y significativos están el empleo de micorrizas y bacterias fijadoras de nitrógeno más la fertilización con $\mathrm{P}$, sobresaliendo el siguiente tratamiento: $200 \mathrm{gr} \mathrm{ha}^{-1}$ (usando micorrizas y bacterias fijadoras de nitrógeno); la variable respuesta en común de los autores mencionados en metodología fue el rendimiento del grano. Los resultados obtenidos por la mayoría de autores muestran que el rendimiento del grano mejora significativamente en la interacción de micorrizas y diazótrofos más la fertilización química; producto del tratamiento mencionado anteriormente, se aumentó un $37 \%$ el rendimiento del maíz $\mathrm{kg} \mathrm{ha}^{-1}$, en virtud a estos resultados se concluye que lo más adecuado sería tomar en cuenta para aplicarla sobre el cultivo de maíz.

How to cite this article: Zambrano JJP, García VSG (2021). Influence of Dosages of Biofertilizers Composed of Mycorrhizae and Diazotrophs on the Corn 


\section{Introducción}

El maíz es un cultivo muy importante a nivel mundial, se usa en el consumo humano, alimentación de ganado y en la industrial [1].

En la mayoría de los suelos tropicales, el principal nutriente limitante es el nitrógeno; además el fósforo es, luego del N, el nutriente más relevante en la nutrición del cultivo, y de su disponibilidad dependen algunos procesos fisiológicos de las plantas de maíz, incluidos nutrientes acompañantes, que al final tienden a repercutir en los rendimientos del cultivo $[2,3]$.

El maíz duro seco en Ecuador está localizado principalmente en la región costa, en las provincias de Los Ríos, Guayas y Manabí las mismas concentran el 81.9\% de la superficie total cosechada de este producto [4].

En Ecuador, los agricultores aplican conocimientos empíricos, como la quema de residuos agrícolas (rastrojo de maíz), a pesar de que se aporta una gran cantidad de carbono al suelo, conlleva a ciertos impactos ambientales como la desaparición parcial o total de la población microbiana, además de una notable disminución de materia orgánica $[5,6]$.

El uso excesivo de fertilizante comercial nitrogenado puede afectar negativamente la absorción de nutrientes como Zn, Ca y K [7].

Para resolver problemas relacionados al rendimiento, se está imponiendo el redimensionamiento del uso de biotecnologías, sugiriéndose el uso de biofertilizantes y estimuladores de crecimiento [8].

El nitrógeno es un elemento que debe ser incorporado a través de la fertilización química o por medio de la fijación biológica llevada a cabo por microorganismos, de modo que, las bacterias simbióticas fijadoras de nitrógeno han sido ampliamente utilizadas para la elaboración de inoculantes, constituyéndose en una alternativa viable para mejorar el rendimiento de los cultivos [9].

Se ha planteado sustituir el uso excesivo de fertilizantes químicos, a través del uso de bacterias fijadoras de nitrógeno y hongos micorrízicos en complemento a la fertilización química. Actualmente han surgido alternativas basadas en el aprovechamiento de los recursos autóctonos y en el ciclaje de nutrientes como son el uso de abonos orgánicos: estiércoles, compost, lodos residuales y biofertilizantes; ya que esto supone un mejor crecimiento y desarrollo vegetativo de los cultivos [10-13].

Diversos hongos del suelo desarrollan actividades que benefician la nutrición y salud de las plantas, tanto en ecosistemas naturales como en agricultura, tales hongos beneficiosos son conocidos como micorrizas [14].

Se le denomina micorriza a la asociación que se da entre algunos hongos del suelo y las raíces de la gran mayoría de plantas. El hongo se integra tanto en la raíz, que llega a ser parte de ella, estableciéndose una relación de dependencia mutua hongo-planta, la mayoría de las plantas presentes demuestran esta simbiosis [15]. El hongo coloniza las raíces, sin causar daño alguno a la planta y posteriormente desarrolla una red de hifas externas que se extienden y ramifican en el suelo. La principal característica morfológica de estas micorrizas son los arbúsculos, estructuras típicas de la colonización que el 
hongo desarrolla en el interior de las células de la corteza de la raíz por ramificación de sus hifas $[14,15]$.

La adecuada selección de hongos y la posterior manipulación de las micorrizas permiten obtener plantas de calidad, aumentando sustancialmente su viabilidad [16].

Algunas plantas establecen una relación estrecha y persistente con bacterias fijadoras de nitrógeno; esta simbiosis, proporciona beneficios durante la vida en común a ambos simbiontes, se realiza en nódulos radiculares, en los cuales el nitrógeno atmosférico se fija y se proporciona a la planta en forma de compuestos orgánicos nitrogenados. De esta simbiosis la planta obtiene nitrógeno y la bacteria, ácido málico en su forma ionizada (malato) y refugio [17].

Existen bacterias capaces de fijar nitrógeno y solubilizar fósforo, lo que ha despertado el interés de investigadores por conocer sobre los procesos metabólicos por medio de los cuales estos microorganismos brindan sus beneficios a la agricultura y al ambiente. La capacidad de estos microorganismos para producir compuestos orgánicos, realizar fijación biológica de nitrógeno y solubilizar fosfatos, son actividades que efectúan mediante enzimas como nitrogenasas y fitasas, con un efecto positivo en la promoción del crecimiento vegetal y en el aumento del potencial productivo [18].

Además [18] mencionan que la capacidad de estos microorganismos para producir compuestos orgánicos, realizar fijación biológica de nitrógeno y solubilizar fosfatos, son actividades que efectúan mediante enzimas como nitrogenasas y fitasas, con un efecto positivo en la promoción del crecimiento vegetal y en el aumento del potencial productivo, por lo tanto facilita la fijación biológica de nitrógeno.

Las bacterias con potencial para fijar nitrógeno, provenientes de suelos amazónicos tendrían ventajas comparativas con respecto a cepas fijadoras provenientes de otros ecosistema [19].

La relación que se produce entre la bacteria y la planta es simbiótica, es decir, donde ambos individuos se ayudan y benefician mutuamente, las bacterias fijan el nitrógeno atmosférico y lo incorporan a la base proteica del vegetal, por el contrario, este último da cobijo y ambiente propicio para el correcto desarrollo del microorganismo en su interior [20].

Los biofertilizantes elaborados con hongos micorriza, son productos benéficos, que se asocian a las raíces de las plantas y favorecen su nutrición [21]. El uso de microorganismos rizosféricos como una biotecnología se ha llevado a la práctica mediante la inoculación de semillas [22].

Este artículo de revisión tiene como objetivo, recopilar información acerca de los beneficios que brinda la aplicación de una correcta dosificación de biofertilizantes a base de micorrizas y bacterias fijadoras de nitrógeno sobre el cultivo de maíz.

\section{Metodología}

La información recopilada se extrajo de diferentes bases de datos en línea que contenían trabajos realizados en la temática abordada en este artículo, a continuación se da a conocer la metodología utilizada por varios autores. 
Álvarez et al. [23] llevaron a cabo un ensayo en Buenos Aires, entre los años 2006 y 2007 , donde los tratamientos fueron, $200 \mathrm{gr} \mathrm{ha}^{-1}$ de micorrizas y bacterias fijadoras de nitrógeno, previo al momento de la siembra (la inoculación fue tratada con el biofertilizante Crinigan) y un testigo como opción orgánica; en la opción convencional se utilizó $\mathrm{P}$ a dosis de 0 y $20 \mathrm{~kg} \mathrm{ha}^{-1}$, se determinó la producción del grano (número de granos y peso individual del grano)

Ferraris et al. [24] evaluaron el efecto en el desarrollo vegetativo y finalmente el productivo que conlleva aplicar micorrizas en el cultivo de maíz, utilizaron el biofertilizante Crinigan para la inoculación de micorrizas a una dosis de $8 \mathrm{~g} / \mathrm{kg}$ de semilla de maíz.

Ferraris et al. [25] trabajaron en un ensayo con gramíneas donde aplicaron micorriza y diazótrofos a través del biofertilizante Crínigan, evaluaron un testigo absoluto y el segundo fue la aplicación del biofertilizante a una dosis de $8 \mathrm{~g} / \mathrm{kg}$ de semilla.

Ferraris et al. [26] emplearon un ensayo, utilizando micorrizas y diazotrofos; continuación, los tratamientos: T1: Testigo Sin fertilizante; T2: Testigo P16 S5 kg ha ${ }^{-1}$; T3: Testigo P16 S5 N120 kg ha ${ }^{-1}$; T4: Micorrizas Sin fertilizante; T5: Micorrizas P16 S5 kg ha $^{-1}$; T6: Micorrizas P16 S5 N120 kg ha ${ }^{-1}$.

Uribe et al. [27] realizaron un trabajo cuyo objetivo fue comparar la aplicación de micorrizas (Glomus intraradices) en dosis de $1.0 \mathrm{~kg} \mathrm{ha}^{-1}$, Azospirillum brasilense en dosis de $350 \mathrm{~g} \mathrm{ha}^{-1}$ y la fitohormona Brassinoesteroide en dosis de $30 \mathrm{~g} \mathrm{ha}^{-1}$, con la aplicación de fertilizantes químicos convencionales. Sus variables respuestas fueron: altura de planta, días a floración masculina y rendimiento.

Martín et al. [28] realizaron un estudio de los siguientes tratamientos: barbecho natural, Canavalia, Canavalia ensiformis (L.) D.C., sembrada para ser utilizada como abono verde, en rotación con maíz, se sembró canavalia y al maíz se le aplicó la cepa de HMA Glomus hoilike por la técnica de recubrimiento de semillas. Las variables evaluadas fueron: colonización micorrízica del maíz en presencia de fertilizantes químicos, rendimiento y porcentaje de colonización por hongos micorrízicos arbusculares en plantas de maíz sin influencia de la fertilización química y el funcionamiento fúngico en la Canavalia ensiformis y el barbecho.

Pérez et al. [29] efectuaron un experimento para conocer la densidad, abundancia y diversidad de especies de hongos micorrízicos arbusculares asociadas al cultivo de maíz, utilizando frijol nescafé (Mucuna deeringiana Merr.) como abono verde/cultivo de cobertura (AVCC). Se aplicaron cuatro tratamientos usando y sin usar AVCC: inoculación con micorrizas arbusculares, aplicación de fertilizante orgánico foliar, inoculación con micorriza+fertilizante orgánico foliar, y testigo. Para inocular $1 \mathrm{~kg}$ de semillas de maíz se humedeció con aproximadamente $100 \mathrm{~mL}$ de agua, estas fueron peletizadas con $0.250 \mathrm{~kg}$ de inóculo micorrízico y se dejaron secar por toda una noche. Al siguiente día se sembraron en los tratamientos: micorriza y micorriza+foliar evitando la exposición directa al sol.

Sajedi et al. [30] realizaron un experimento en Arak, Irán, en el año 2006; los tratamientos incluyen el riego en tres niveles, al 100, 75 y 50\% (equivalente al requerimiento de la planta de maíz), inoculación de micorrizas en el cultivo de maíz en dos niveles (inoculación con $G$. intraradices y sin inoculación) que se inocularon en la siembra de 
semillas, y zinc de la fuente de sulfato de zinc a tres niveles (control, $25 \mathrm{~kg} \mathrm{ha}^{-1}$ y 45 $\mathrm{kg} \mathrm{ha}^{-1}$ ).

Khoshnaz et al. [31] realizaron un experimento sobre el cultivo de maíz. Los tratamientos consistieron en regímenes de riego con tres niveles asignados a principales parcelas y uso combinado de micorrizas y bacterias estabilizadoras de fosfato con cuatro niveles a subparcelas. Las variables que estudiaron fueron: el índice de área foliar, porcentaje de simbiosis, el número de semillas por fila de mazorca de maíz, el número de semillas por mazorca y el rendimiento $\mathrm{kg} \mathrm{ha}^{-1}$.

Cabrales et al. [32] trabajaron en un ensayo de maíz en Guarico, Venezuela, utilizaron 4 especies de hongos del filo Glomeromycota reportadas por Toro (2007) como inóculos nativos de suelos de sabana del estado Guárico (Scutellospora pellucida, Scutellospora calospora, Glomus leptotichum y Acaulospora mellea) y la mezcla de estos, además de la incorporación de $\mathrm{P}\left(0,27,54\right.$ y $80 \mathrm{~kg} \mathrm{ha}^{-1}$ de P2O5). Se dispuso en el fondo de cada sitio ocho gramos del inóculo. Todos los inóculos contenían 150 esporas $/ 100 \mathrm{~g}$ de suelo. Se evaluó la cuantificación del P y $\mathrm{N}$ absorbido por la planta y se midió en la hoja opuesta a la mazorca, esto se hizo mediante extracción por solución binaria, además se evaluó el rendimiento del grano.

\section{Desarrollo y Discusión}

A continuación se detallan los resultados obtenidos, sobre la productividad del maíz, en diferentes trabajos; por los autores que se muestran en metodología.

Álvarez et al. [23] observaron que la inoculación con micorrizas y bacterias fijadoras de nitrógeno permitió mejorar la producción en grano respecto a los tratamientos no inoculados. La producción de grano varió entre 1730 y $2378 \mathrm{~kg} \mathrm{ha}^{-1}$, mostrando diferencias significativas entre tratamientos. Los incrementos de rendimientos sobre el testigo fueron del 28,16 y $37 \%$ para los tratamientos con $\mathrm{P}$, con micorrizas y la combinación de ambos, respectivamente.

Ferraris et al. [24] reportaron que los rendimientos en el cultivo de maíz fueron significativas y crecientes, bajo un adecuado sistema productivo, con respuestas a la inoculación, fertilización fósforo-azufrada, alta dosis de nitrógeno y uso de fungicidas. Esta tendencia propone así la integración prácticas agronómicas que demuestran ser promisorias.

Ferraris et al. [25] no encontraron significancia entre los tratamientos en cuanto a las variables de altura y vigor de planta. Se determinaron diferencias significativas en los rendimientos, a favor del tratamiento inoculado con micorrizas y bacterias fijadoras de nitrógeno en el cultivo de maíz.

Ferraris et al. [26] obtuvieron datos a ambos factores que estudiaron, lo que mostró un comportamiento claro, sin interacción de inoculación con micorrizas y bacterias fijadoras de nitrógeno x fertilización química en cuanto a rendimientos del cultivo de maíz, lo que difiere a los resultados obtenidos por [23-25], quienes obtuvieron significancia en la interaccion de micorrizas, bacterias fijadoras de nitrógeno y fertilización química en cuanto al rendimiento del maíz. En cambio, se determinaron diferencias significativas 
por la inoculación con micorrizas y la inoculación con micorrizas más el agregado de fertilizantes.

Uribe et al. [27] no encontraron diferencias estadísticas significativas en el cultivo de maíz entre los tratamientos evaluados, es decir, tanto los microorganismos benéficos como la fitohormona, la fertilización química y el testigo absoluto tuvieron un resultado similar, lo que contrastan con los reportados por quienes indican que mediante el uso de micorriza se mejora el crecimiento vegetal. En la variable del área foliar no se encontraron diferencias estadísticas significativas entre los tratamientos evaluados. En cuanto al rendimiento del maíz V-539 observado en el período de evaluación se registraron diferencias estadísticas significativas entre los años de evaluación, el mayor rendimiento se registró en 2001 con $5.18 \mathrm{t} \mathrm{ha}^{-1}$, el cual fue estadísticamente diferente y superior; sin embargo, hay que tener en cuenta que las condiciones climáticas fueron diferentes durante el experimento.

Martín et al. [28] analizaron los resultados del comportamiento de las variables de funcionamiento fúngico, se observó que también la canavalia fue superior al barbecho natural en cuanto al porcentaje de colonización radical y al número de esporas de HMA presentes en el suelo. Se encontraron diferencias estadísticamente significativas entre los rendimientos de los tres tratamientos de las parcelas principales en ausencia de fertilización química. Así, los tratamientos de canavalia y canavalia+HMA fueron semejantes entre sí y presentaron rendimientos superiores en el cultivo de maíz; no obstante, en este ensayo se utilizó la canavalia como abono verde, quienes han obtenido significancia en presencia de fertilizantes químicos debido a que se han limitado al uso de los mismos, sin añadir abonos verdes como factor de estudio, similar que la investigación realizada por Pérez et al. [29] a diferencia de la leguminosa utilizada.

Pérez et al. [29] dieron a conocer que la densidad de esporas y el porcentaje de colonización micorrícica no variaron con significancia estadística entre parcelas con y sin abono verde/cultivo de cobertura (AVCC); no obstante, se observó que el número de esporas fue cerca de 30\% más alto en parcelas con AVCC. El AVCC tuvo un efecto positivo y altamente significativo sobre la riqueza de especies y el índice de diversidad. El efecto de micorriza fue significativo sobre el porcentaje de colonización micorrícica y no tuvo una influencia significativa sobre el número de esporas, la riqueza de especies y el índice de diversidad.

Sajedi et al. [30] mostraron que el estrés por sequía fue efectivo en los rasgos agronómicos y el rendimiento de grano, se obtuvo el máximo rendimiento de grano en el riego de control, mediante el uso de hongos micorrícicos y sulfato de zinc, los rasgos deseados se incrementaron individualmente. Los efectos duales de hongos y sulfato en el rendimiento de grano aumentaron, los efectos de triple interacción de los tratamientos (riego, hongos y sulfato de zinc) aumentaron el rendimiento de grano, de modo que se obtuvieron los rasgos agronómicos máximos y el rendimiento de grano por efecto de triple interacción de riego de control, $25 \mathrm{~kg} \mathrm{ha}^{-1}$ de sulfato de zinc e inoculación con hongos $G$. intraradices; en este experimento se utilizó el zinc, lo que resalta de los demás trabajos realizados, sin embargo, se obserba que los beneficios de las micorrizas fueron mejor aprovechadas sumándole la fertilización química. 
Khoshnaz et al. [31] obtuvieron resultados sobre el cultivo de maíz que mostraron que los efectos de los regímenes de riego y el uso combinado de micorrizas y fertilizantes de fósforo en el índice de área foliar, porcentaje de simbiosis, el número de semillas por fila de mazorca de maíz, el número de semillas por mazorca y el rendimiento de semillas fueron significativos; esta investigación concuerda con los resultados obtenidos por [23-26], a pesar de que fueron trabajos realizados en diferentes años y en diferentes localidades, bajo condiciones edafoclimáticas distintas, el resultado fue similar, lo que muestra con mas seguridad que el uso de micorrizas y fertilización química aumenta el rendimiento del maíz.

Cabrales et al. [32] indicaron que, cuando se compararon las medias de absorción de nitrógeno, se pudo observar que sin la inoculación de micorrizas y con inoculación de micorrizas, hay diferencias estadísticas altamente significativas, pero entre las parcelas inoculadas no hay diferencia en la toma de $\mathrm{N}$ por la planta de maíz. Sin embargo, la mejor absorción se logró cuando se utilizó el consorcio de especies nativas. En cuanto al rendimiento, el análisis del factor dosis de fósforo arrojó diferencias significativas entre sus medias $\left(\mathrm{p}<0.05\right.$ ), siendo $54 \mathrm{~kg} \mathrm{ha}^{-1}$ la mejor dosis cuya producción fue de $3325.9 \mathrm{~kg} \mathrm{ha}^{-1}$.

\section{Conclusiones}

En la mayoría de las investigaciones que se han adjuntado en este artículo de revisión, se da a conocer a través de los resultados, que el uso de una adecuada dosificación de biofertilizantes a base de micorrizas y bacterias fijadoras de nitrógeno en complemento a la fertilización química, pueden influir positivamente en el desarrollo vegetativo y productivo del cultivo de maíz, además mediante el uso de estos microorganismos es posible disminuir la dosificación de fertilizantes a base de P. De las investigaciones revisadas, varias concuerdan en su metodología y resultados, sin embargo el uso de micorriza y bacterias fijadoras de nitrógeno a una dosis de $200 \mathrm{~g} \mathrm{ha}^{-1}$ fue el resultado más notable, incrementando un $37 \%$ el rendimiento del maíz; por lo que lo más adecuado sería tomar en cuenta esta dosificación para aplicarla sobre el cultivo de maíz.

\section{Agradecimientos}

Agradecemos a Dios por brindar oportunidades tan preciadas para nuestras vidas, también a las autoridades de la ULEAM y en especial al Ph.D. Ángel Guzmán Cedeño, quién nos motivó a ser perseverantes durante este trayecto.

\section{References}

[1] Granillo R. Caracterización de la cadena de valor del maíz. Ingenio Conciencia [Internet]. 2018;5(9). https://doi.org/10.29057/ess.v5i9.2899

[2] Remache M, Carrillo M, Mora R, Durango W, Morales F. Absorción de macronutrientes y eficiencia del N, en híbrido promisorio de maíz. Patricia Pilar, Ecuador. Agro. Costarricense [Internet]. 2017;41(2):103-115. https://revistas.ucr.ac.cr/index.php/agrocost/article/view/31303/31013 
[3] Correndo A, García F. Bases de la nutrición del cultivo de maíz: Técnicas probadas para una producción rentable. 1ra ed. [Internet]. 2014 Retrieved from http://lacs.ipni.net/ipniweb/region/lacs. nsf/eOf085ed5f091b1b852579000057902e/251e0b2ce526f8b1032580360060025a/protectlTU। textdollarFILE/Bases\{\%\}20para\{\%\}20la\{\%\}20nutricion\{\%\}20de\{\%\}20maiz\{\%\}20-\{\%\}20CREA\{\%\}202014. pdf

[4] INEC (Instituto Nacional de Estadística y Censos). Encuesta de Superficie y Producción Agropecuaria Continua, 2018. Boletín técnico [Internet]. 2019; 1:10. https://www. ecuadorencifras.gob.ec/documentos/web-inec/Estadisticas_agropecuarias/espac/espac-2018/ Presentacion\{\%]20de[\%]20principales\{\%\}20resultados.pdf

[5] Marcillo F, Mendieta R. Utilización del hongo Pleurotus sapidus en la degradación lignocelulósica del rastrojo de maíz para la elaboración de abono en agricultura orgánica [Tesis de grado en internet]. Calceta, Ecuador: ESPAM; 2013. Available from: http://repositorio.espam.edu.ec/bitstream/42000/166/ 1/RONALD\{\%\}2OMENDIETA-\{\%\}2OFABIAN\{\%\}2OMARCILLO.pdf

[6] Rozas S, Eyherabide M, Echeverría $\mathrm{H}$ et al. ¿Cuál es el estado de la fertilidad de los suelos argentinos? Fertilizar. 2013;62-72. https://inta.gob.ar/sites/default/files/inta.estado-fertilidad-suelos-argentinos.pdf

[7] Zamudio B, Tadeo M, Espinoza A et al. Eficiencia agronómica de fertilización al suelo de macro nutrimentos en híbridos de maíz. Rev. Mex. Cienc. Agríc. 2015;6(7):1557-1569.

[8] Morejón M, Herrera J, Ayra P et al. Alternativas en la nutrición del maíz transgénico FR-Bt 1 de (Zea mays L.): respuesta en crecimiento, desarrollo y producción. Cultivos tropicales. 2017;38:145-155.

[9] Moreno L, Pérez A, Ramírez M, Franco M. Efecto de la temperatura de almacenamiento sobre la viabilidad de bacterias simbióticas fijadoras de nitrógeno utilizadas en la elaboración de inoculantes biológicos para arveja (Pisum sativum) y soya (Glycine max). Rev. Colomb. Biotecnol. 2014;16(2):45-56.

[10] Padrón L, Torres D, Contreras J, López M, Colmenares C. Aislamientos de cepas fijadoras de nitrógeno y solubilizadoras de fósforo en un suelo alfisol venezolano. Rev. Mex. Cienc. Agríc. 2012;3(2):285-297.

[11] Aguilar C, Escalante J, Aguilar I, Mejía J, Conde V, Trinidad A. Rendimiento y rentabilidad de maíz en función del genotipo, biofertilizante y nitrógeno, en clima cálido. Tropical and Subtropical Agroecosystems. 2015;18(2)151-163.

[12] Montejo D, Casanova F, García M, Oros I, Díaz V, Raymundo E. Respuesta foliar y radical del maíz a la fertilización biológica-química en un suelo Luvisol. Agron. Mesoam. 2018;29(2):325-341.

[13] Lauriano-Barajas J, Vega-Frutis R. Infectivity and effectivity of commercial and native arbuscular mycorrhizal biofertilizers in seedlings of maize (Zea mays). Botanical Sciences. 2018;96(3):395-404.

[14] Barea J, Pozo M, Aguilar C. Significado y aplicación de las micorrizas en agricultura. Agricultura. 2016:746-751.

[15] Garay C. Las micorrizas ¿Qué son?. Tecno gro. 2014:97. Disponible en https://tecnoagro.com.mx/no. -97/las-micorrizas-que-son.

[16] Díaz G, Torres P, Sánchez F, García G, Carrillo C. Primeras tesis doctorales sobre micorrizas. Eubacteria. 2016;36:39-43.

[17] Calvo S. Bacterias simbióticas fijadoras de nitrógeno. CT. 2011;3:173-186

[18] Corrales L, Lozano L, Gómez M, Ramos S, Rodríguez J. Bacillus spp: una alternativa para la promoción vegetal por dos caminos enzimáticos. Nova. 2016;15(27):45-65.

[19] Mantilla A, Cardona G, Peña C, Murcia U, Rodríguez M, Zambrano M. Distribución de bacterias potencialmente fijadoras de nitrógeno y su relación con parámetros fisicoquímicos en suelos con tres coberturas vegetales en el sur de la Amazonia colombiana. Biol. Trop. 2009;57(4):915-927.

[20] López J, Boronat R. Aspectos básicos de la fijación de nitrógeno atmosférico por parte de bacterias. Estudio en el laboratorio de educación secundaria. Eureka. 2016;13(1):203-209.

[21] Tadeo M, García J, Alcántar H et al. Biofertilización en híbridos de maíz androestériles y fértiles para los Valles Altos de México. Tierra latinoamericana. 2017;35(1):66-72.

[22] Peña H, Reyes I. Aislamiento y evaluación de bacterias fijadoras de Nitrógeno y disolventes de fosfatos en la promoción del crecimiento de la lechuga (lactuca sativa L.). Interciencia. 2007;32(8):560-565.

[23] Álvarez C, Scianca C, Barraco M, Klappenbach J. Fertilización con fósforo e inoculación con micorrizas en girasol en sistemas convencionales y de producción orgánica. Boletín técnico. 2006:34.

[24] Ferraris G, Couretot L. Inoculación con micorrizas en maíz evaluación bajo diferentes niveles tecnológicos y dosis de nitrógeno. Boletín técnico. 2009;2.

[25] Ferraris G, Couretot L. Microorganismos promotores de crecimiento en sorgo Sorghum bicolor (Linn.): efecto de las micorrizas sobre el crecimiento y la producción. Boletín técnico. 2011;1.

[26] Ferraris G, Couretot L. Evaluación de la inoculación con micorrizas en maíz bajo diferentes ambientes de fertilidad. Boletín técnico. 2006:1.

[27] Uribe G, Dzib R. Micorriza arbuscular (Glomus intraradices), Azospirillum brasilense y Brassinoesteroide en la producción de maíz en suelo luvisol. Agric. Tec. 2006;32(1):67-76. 
[28] Martín G, Costa J, Urquiaga S, Rivera R. Rotación del abono verde Canavalia ensiformis con maíz y micorrizas arbusculares en un suelo nitisol ródico éutrico de Cuba. Agronomía Trop. 2007;57(4):313-321.

[29] Pérez Y, Álvarez J, Mendoza J, Pat J, Gómez R, Cuevas L. Diversidad de hongos micorrícicos arbusculares en maíz con cultivo de cobertura y biofertilizantes en Chiapas, México. Gayana Bot. 2012;69(1):46-56.

[30] Sajedi N, Shirani A, Sajedi A, Khan H. Effect of mycorrhiza (Glomus intraradices) and zinc on morphological and agronomic traits of corn (Zea mays L.) under different levels of soil moistures. Agris. 2011;7(2):21-33.

[31] Khoshnaz P, Mani M, Nazli D. Effect of mycorrhiza and phosphate solublizing bacteria on yield of corn (Zea mays L.) (KSC 704) under different irrigation regimes. Ikufiziyuluzhīi Giyāhān-i Zirā'ī. 2019;13(3):359-376.

[32] Cabrales E, Toro T, López-Hernández D. Efecto de micorrizas nativas y fósforo en los rendimientos del maíz en Guárico, Venezuela. Temas agrarios. 2016;21(2):21-31. 